\title{
Utilization of banana stalk fiber as reinforcement in low density polyethylene composite
}

Babatunde Oluwole Ogunsile ${ }^{1}$, Temitope Gbemi Oladeji ${ }^{2}$

\author{
${ }^{1}$ Department of Chemistry, University of Ibadan, Nigeria. \\ e-mail: ogunsile@yahoo.com \\ ${ }^{2}$ Department of Chemistry, University of Ibadan, Nigeria \\ e-mail: trueteepsy@yahoo.com
}

\begin{abstract}
Natural fibers could serve as viable and abundant alternatives to the expensive and non - renewable synthetic fibers as reinforcement in thermoplastic composites. The potentiality of banana stalk fiber at reinforcing a low density polyethylene matrix was examined in this study. Fibers were extracted from the stalk of banana plant and characterized for its chemical composition and fiber contents. The fibers were modified by pulping with caustic soda to increase it wettability. The fiber dimension was measured using a binocular light microscope. FTIR spectra was used to identify the functional groups of modified and unmodified fibers. The composites were produced using a single - screw extruder, pelletized and then processed into test specimen samples by injection molding. The fiber volume in the polymer matrix was varied from 5.4 to $20 \%$. The effects of chemical treatment and increasing fiber content on the moisture absorption and mechanical properties of the composites were examined. The results showed that fiber of banana plant were characterized by medium to long fiber length $(2.84 \mathrm{~mm})$. The lignin content $(7.99 \%)$ was relatively low indicating a lower value of chemical consumption in the modification step. The SEM micrograph of the composite cross section showed good fiber/matrix interfacial bonding. The water absorption capacity of the composites increased with increase in fiber loading while the treated fibers showed a reduction in hydrophylicity of the composites. The treated fibers showed improved tensile strength and can thus be utilized in the production of composites with better properties
\end{abstract}

Keywords: Banana fiber, composites, reinforcement, polyethylene, mechanical properties

\section{INTRODUCTION}

There has been rapidly growing interest in fiber reinforced polymer composites in their applications both in industry and in fundamental research [1]. Fiber reinforced composites have high tensile, flexural, impart and compression strength over the synthetic polymers and copolymers without reinforcement. Various synthetic fibers such as glass, carbon, aluminum oxide, boron fibers, have been used commercially in reinforcing various polymeric materials. However, researches in recent years have been focused on the use of natural fibers as a viable and biodegradable alternative in reinforcing plastics [2].

Natural fibers are readily available and abundant in nature. These fibers can be used to reinforce polymers to obtain low density with specific strength materials. Natural fibers have the advantages of low density, low cost, non-toxicity, recyclability, biodegradability and environmental friendliness over the traditionally applied synthesized fibers [3,4]. Fiber-reinforced composites have been used in furniture, packaging, assembly boards, paneling, sporting goods, fencing, electrical, kitchen to civil constructions, automobile and marine industries, military purposes, space and aircraft manufacturing [5]. The use of cellulosic fibers such as sisal, pineapple, abaca, coir, banana, jute, flax, hemp, henequen and others in composites as reinforcements have been reported in the literature $[6,7]$.

Growing attention is being paid to banana fiber as a promising reinforcing material because it is relatively inexpensive, abundantly available and the energy requirement in their extraction is low, which has a considerable engineering advantage [5]. Banana is a lignocellulosic bast fiber which is obtained from the pseudo-stem of the banana plant (Musa sepientum). It is a suitable fiber with relatively good mechanical properties [8-10]. Banana fibers have been used in reinforcing various composite materials including epoxy resin, vinyl ester, polyester, polypropylene and polyethylene [8-13] composites. The fiber was also 
used with other fibers such as jute, hemp and glass, sisal and flax [14-17]. However, the weak compatibility between fibers and polymer matrix due to their poor wettability and weak interfacial bonding, the low dispersion degree of the fibers, as well as its poor moisture resistance, generally leads to low performance materials, limiting their use [18]. Size, geometry and dispersion of filler particles in the matrix are other factors which can largely affect the composite properties. Surface modification of the fibers and/or polymer functionalization, as well as addition of compatibilizers is required in order to improve the interfacial interactions between hydrophobic polymer and hydrophilic fibers [18]. Therefore, to improve the fiber-matrix adhesion, a pretreatment of the fiber surface or the incorporation of surface modifier during processing is required. Although, banana pseudostems have been used extensively in reinforcing polymer, the use of the stalk is limited in the literature [19]. In this study, the reinforcing potential of banana stalk in polymer matrix was examined. Banana stalk fiber (BSF) was subjected to chemical pulping and used as reinforcement in low density polyethylene composites. The effects of fiber loading and pretreatment on the physical and mechanical properties of the composites were determined and reported.

\section{MATERIALS AND METHODS}

\subsection{Materials}

Banana stalk was obtained from a local market at Oje in Ibadan, Oyo state, Nigeria. The stalks were first washed thoroughly with $2 \%$ detergent water and then peeled. Fibers were extracted manually from these stalks with the aid of a knife (Figure 1a). The fiber bundles were air dried at room temperature for about 72 hours before being cut into chips of about $2 \mathrm{~cm}$ (Figure 1b) and then oven dried at $60{ }^{\circ} \mathrm{C}$ for $24 \mathrm{hrs}$. The dried fiber was milled in a Thomas Wiley grinding machine and screened to obtain fiber dimension of about $2 \mathrm{~mm}$ in size, making it ready for mixing with the polyethylene pellets. The dried fibers were designated as untreated fibers. The Low Density Polyethylene (LDPE) was supplied in pellet form by Sasol Polymers, Johannesburg, South Africa. It has a Melt Flow Index MFI of 7.0 g/10min (ASTM D-1238), a melting point of $106{ }^{\circ} \mathrm{C}$, an average molar mass (MW) of $96000 \mathrm{~g} \mathrm{~mol}^{-1}$, and a density of $0.918 \mathrm{~g} \mathrm{~cm}^{-3}$.

\subsection{Chemical composition}

The chemical component of the banana stalk was determined as described in our previous study [20]. ASTM standard method was used for the ash content (D1102-56), alcohol-benzene solubles (D1107-56), one percent caustic soda solubles (D1109-56), cold and hot water solubles (D1110-56). The cellulose content was determined using the Kurschner-Hoffer method while the standard method of TAPPI was used for the lignin content.
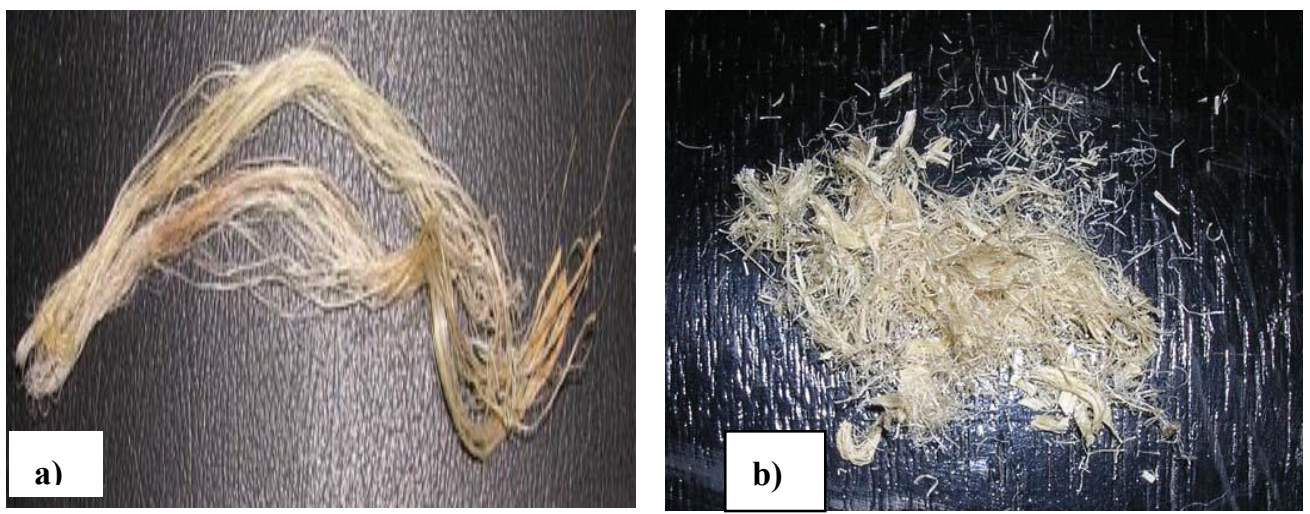

Figure 1: Banana fiber photographs: (a) long fibers extracted from raw stalk and (b) chopped semi dried fibers

\subsection{Fiber dimension}

Some fibers were randomly selected from the chopped banana samples. The fibers were reduced to pieces of about $20 \mathrm{~mm}$ to $40 \mathrm{~mm}$ with the aid of a sharp knife. The fibers were then macerated in a mixture of equal volume (1:1) of glacial acetic acid and $50 \%$ hydrogen peroxide after the method of Franklin [21] in order to ease their liberation. The macerated samples were left for about 3 weeks at room temperature and then disintegrated by shaking in a covered tube. The liberated fibers were prepared on a slide and the fiber 
length (L), fiber diameter (D), lumen width (d) and cell wall thickness were obtained using stage and eye piece micrometer on a binocular light microscope. An average of 25 samples were measured.

\subsection{Surface pretreatment}

The chopped banana samples were pulped in a 10-L electrically heated, thermostatically controlled stainless steel digester designed after the method of Grant [22]. The sample was placed into the digester with $10 \% \mathrm{NaOH}$ (causic soda) solution at a liquid to solid ratio of about $10: 1$ and a temperature of $120^{\circ} \mathrm{C}$ for 2 hours. It was cooled for $30 \mathrm{~min}$ before the pulped sample was removed. The pulped sample was filtered and then washed thoroughly with tap water and distilled water respectively and then dried.

\subsection{Processing of BSF / LDPE composite}

The untreated banana stalk fiber (BSF) and the low density polyethylene composite mixed by a blending and melt compounding technique, using a locally fabricated single screw extruder machine. The ground sieved banana fiber was oven dried and thoroughly mixed with the appropriate amount of polyethylene (Table 2). The mixed raw material was transferred through the hopper into the extruder which operates with an inlet temperature of $140^{\circ} \mathrm{C}$ while the outlet temperature was about $170{ }^{\circ} \mathrm{C}$. The extruded product was further homogenized as shown in Figure 2 in a two roll mill located at the Nigerian Institute of Leather Science Technology (NILEST), Zaria, Kaduna, where it was melt mixed for a period of 10 min at a temperature of about $160^{\circ} \mathrm{C}$ and a rotating speed of $60-70 \mathrm{rpm}$. The resulting composite was moulded by a hydraulic hot press machine to give a test specimen of about $120 \mathrm{~mm}$ by $7 \mathrm{~mm}$ by $3 \mathrm{~mm}$. A similar processing method was repeated using the pulped banana fiber with the low density polyethylene.

Table 1: Composition of banana fiber / LDPE composite

\begin{tabular}{cccc}
\hline $\mathbf{S} / \mathbf{N}$ & $\begin{array}{c}\text { BANANA FIBER, } \\
(\% \text { VolUME })\end{array}$ & $\begin{array}{c}\text { LDPE, } \\
(\% \text { VolUME })\end{array}$ & ABREVIATION \\
\hline 1 & 0 & 100 & LDPE \\
\hline 2 & 5.4 & 94.6 & $5.4 / 94.6$ BSF-LDPE \\
\hline 3 & 10.5 & 89.5 & $10.5 / 89.5$ BSF - LDPE \\
\hline 4 & 15.4 & 84.6 & $15.4 / 84.6$ BSF-LDPE \\
\hline 5 & 20.0 & 80.0 & $20 / 80$ BSF-LDPE \\
\hline
\end{tabular}

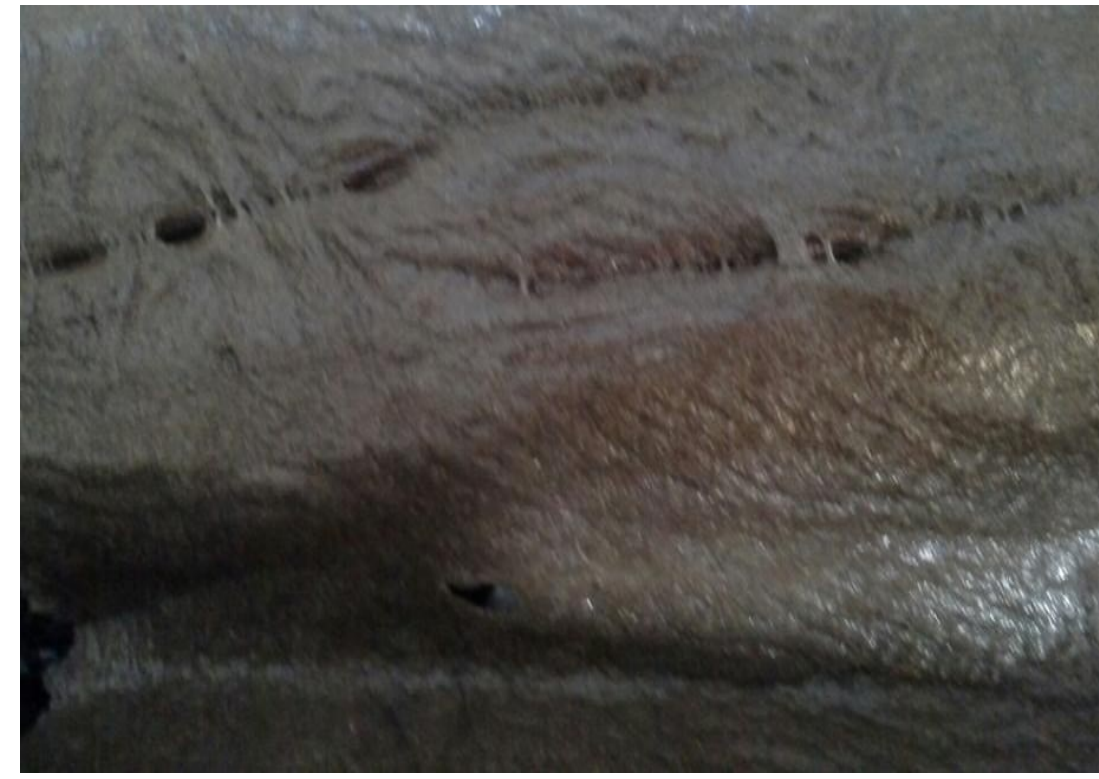

Figure 2: Photograph of the BSF / LDPE homogenized composite from the roll mill 


\subsection{Physical and mechanical properties}

The water absorption (WA) characteristic of the composites was determined manually based on the difference between the weight of test specimen soaked for 24 hours and the oven dry weight test specimen [23]. The thickness swelling (TS) was based on the difference in their thickness before and after soaking in water for 24 hours. The mechanical test was performed using an Instron Testing Machine located at the Kwara State University, Ilorin, Nigeria. Tensile tests was carried out (with test specimen of about 120 $\mathrm{mm}$ by $7 \mathrm{~mm}$ by $3 \mathrm{~mm}$ ) in accordance with the Chinese standard GB/T 1447-1983, at a cross head speed of $0.16667 \mathrm{~mm} / \mathrm{sec}$. Three replicate specimens were tested for each set except for the 10.5/89.5 BSF LDPE composite where a single value was used. The tensile strength, modulus and elongation at break were evaluated from the stress -strain curve.

\subsection{Morphology and FTIR analysis}

The morphology of the banana fiber reinforced low density polyethylene interface was examined using a Scanning Electron Microscope (SEM). Fourier-Transform Infrared Spectroscopy (FTIR, Perkin Elmer Version 10.03.07) was used to obtain some qualitative information about the functional groups and chemical characteristics of banana fiber with and without the pulping treatment. Each spectrum was obtained within the range of $500-4000 \mathrm{~cm}^{-1}$.

\section{RESULTS AND DISCUSSION}

\subsection{Chemical component of the banana stalk}

The chemical component of the banana stalk was determined to be $47.76 \%$ cellulose, $7.99 \%$ lignin and $10.72 \%$ ash. The extractive contents, i.e., alcohol-benzene solubles, cold and hot water solubles and one percent caustic soda solubility were $4.26 \%, 25.65$ and $32.71 \%$ and $22.97 \%$ respectively [20]. The cellulose content of $47.76 \%$ was an indication of an average but tolerable yield. The lignin content was low and desirable suggesting low chemical consumption of liquor during chemical treatment or modification. The ash content and the values of the extractives (apart from the alcohol-benzene solubles) were relatively high, although within the range reported for most non-woods [24]. Thus, it may be necessary to pre-treat the plant in order to remove the extractives before the fiber is processed into composites.

\subsection{Fiber characterisation of the banana stalk}

The results of the fiber dimensions are all presented in Table 2 and the photomicrograph in Figure 3 . The fiber length of $2.84 \mathrm{~mm}$ was similar to $2.87 \mathrm{~mm}$ obtained earlier [20]. The banana fiber can be categorized as a medium to long fibered plants which is expected to have more contact area. The fiber diameter of $0.0416 \mathrm{~mm}$ was within the range of 0.02 to $0.5 \mathrm{~mm}$ for plastic reinforcement [25]. Fiber with small diameter has been associated with large specific surface area at the same fiber weight ratio. [26].

Table 2: Fiber characteristics of the Banana Fiber

\begin{tabular}{cc}
\hline PARAMETER & VALUE \\
\hline Fiber length $(l)$ & $2.84 \mathrm{~mm}$ \\
\hline Fiber diameter $(d)$ & $41.60 \mu \mathrm{m}$ \\
\hline Lumen width & $29.40 \mu \mathrm{m}$ \\
\hline Cell wall thickness (cwt) & $5.20 \mu \mathrm{m}$ \\
\hline Aspect ratio $(\mathrm{l} / \mathrm{d})$ & 68.30 \\
\hline
\end{tabular}




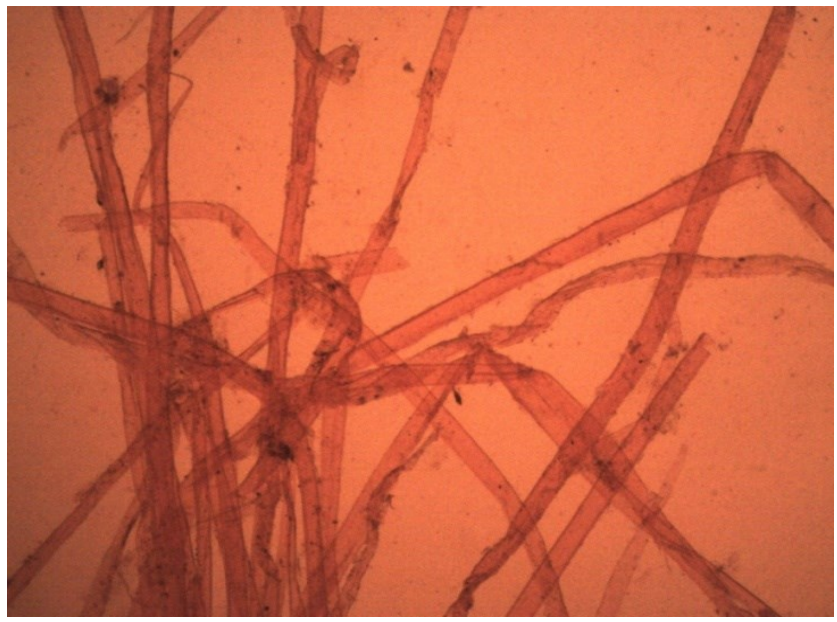

Figure 3: Photomicrograph of banana stalk fiber. (magnification: $x 100$ )

The small diameter of the banana fiber will allow more surface area to be in contact with the LDPE, and thus increases the reinforcing effect. The aspect ratio $(1 / d)$ of 68 obtained in this study is relatively higher than the aspect ratio of 50 reported for alpha-grass [27]. The banana fiber is therefore expected to have a good interfacial bonding with the polymer matrix.

\subsection{Physical properties of the composites}

The water absorption properties of the composites are illustrated in Figure 4. The results showed that the water absorption of the chemically treated fiber-based composites (FBC) was lower than that of the untreated FBC. This suggested that changes in surface chemistry caused a reduction in the affinity of the fibers for water absorption. During chemical pulping of the fiber, hemicellulose and lignin were removed $[23,28]$, thus making the cellulose available for composite formation. The hydroxyl group of the cellulose reacted with the functional group, which in turn bonded to the polymer matrix and thus established a good fiber/matrix bonding interaction [29]. Strong intermolecular fiber-matrix bonding decreases the rate of moisture absorption in biocomposites. Thus, the chemical treatments of the banana fiber resulted in a decrease in the water absorption of the biocomposites.

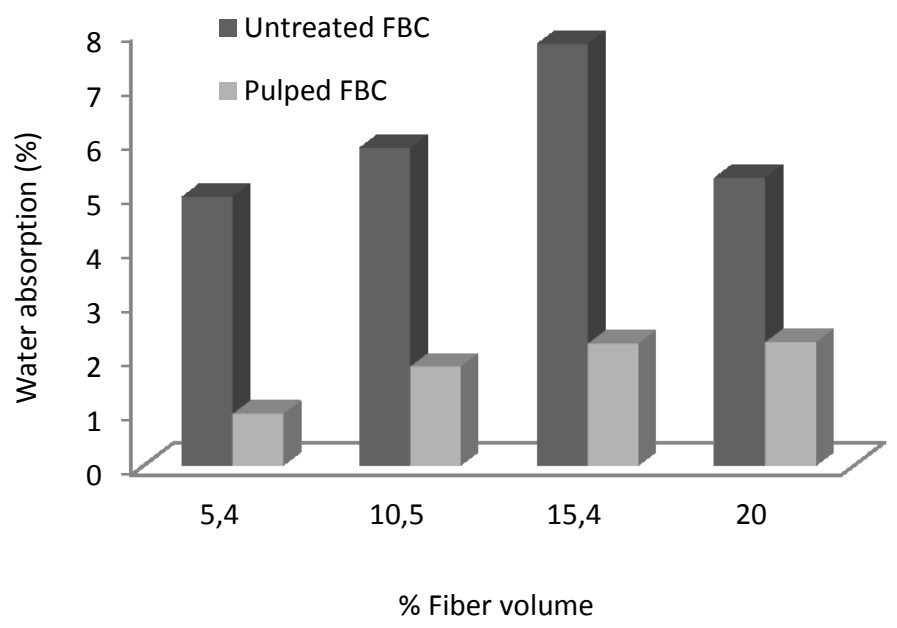

Figure 4: Effect of fiber content on the water absorption properties of the composites.

The thickness swelling of natural fiber based polymer composites is due to the presence of polar groups, which attract water molecules through hydrogen bonding [30]. This phenomenon caused moisture build-up in cell walls (fiber swelling) and at the fiber matrix interface. Treatment of the fibers with caustic 
soda causes the cellulose to collapse and glue together, thereby reducing the water absorption of the composite and its internal swelling. The pulped BSF reinforced LDPE composite showed the lowest thickness swelling (Figure 5) because changes in surface chemistry of the treated BSF causes a reduction in the affinity of the fibers to moisture thereby limiting its swelling within the polymer matrix.

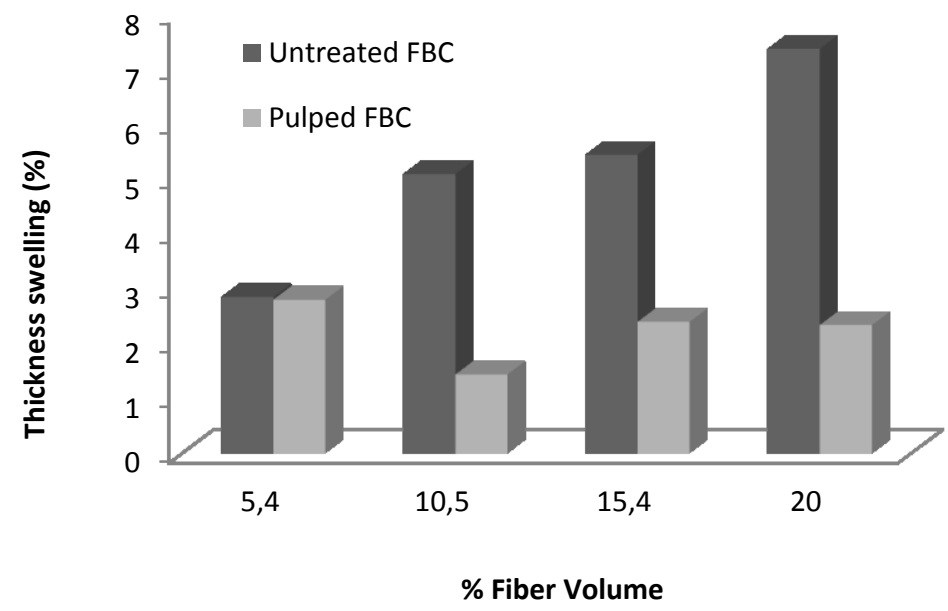

Figure 5: Effect of fiber content on the thickness swelling properties of the composites

\subsection{Mechanical properties of the composite}

The variation of the mechanical properties of the BSF/LDPE composites is shown in Figures 6 and 7 . The tensile strength and modulus of the composites were found to increase with increasing fiber content. This is attributed to the interfacial interaction of the fiber/polymer matrix and the reinforcing efficiency of the fiber through stress transfer from the matrix to the load bearing fibers. Furthermore, the tensile strength and modulus of the treated FBC was improved relatively to the untreated fibers. The pretreatment of the fiber by pulping improved the fiber-matrix interaction, leading to a higher value of modulus and tensile strength. The percentage improvement in the tensile properties of the BSF/LDPE composites is summarized in Table 3. At $10 \%$ fiber loading, the tensile modulus increases by more than $200 \%$. This is quite remarkable. Elongation at break of the treated and untreated composites is shown in Figure 8. The result showed that elongation decreases with increasing amount of reinforcing fiber. This was due to the inability of the reinforcing fiber to elongate unlike the polymer matrix. This may be due to the decreasing deformation on stiffness matrix surface between filler and matrix [31]. The pulped FBC showed relatively higher value of elongation than the untreated BSF. While fiber reinforcement increases the tensile modulus and strength, the elongation of the composite was steadily decreased.

Table 3: Percentage improvement in tensile properties of pulped banana fiber - LDPE composite

\begin{tabular}{ccc}
\hline COMPOSITE & $\begin{array}{c}\text { \% IMPROVEMENT IN TENSI- } \\
\text { LE STRENGTH }\end{array}$ & $\begin{array}{c}\text { \% IMPROVEMENT IN TENSILE } \\
\text { MODULUS }\end{array}$ \\
\hline $5.4 / 94.6$ BSF-LDPE & 18.61 & 46.75 \\
\hline $10.5 / 89.5$ BSF - LDPE & 19.66 & 100.38 \\
\hline $15.4 / 84.6$ BSF-LDPE & 35.94 & 161.23 \\
\hline $20 / 80$ BSF-LDPE & 69.34 & 223.36 \\
\hline
\end{tabular}




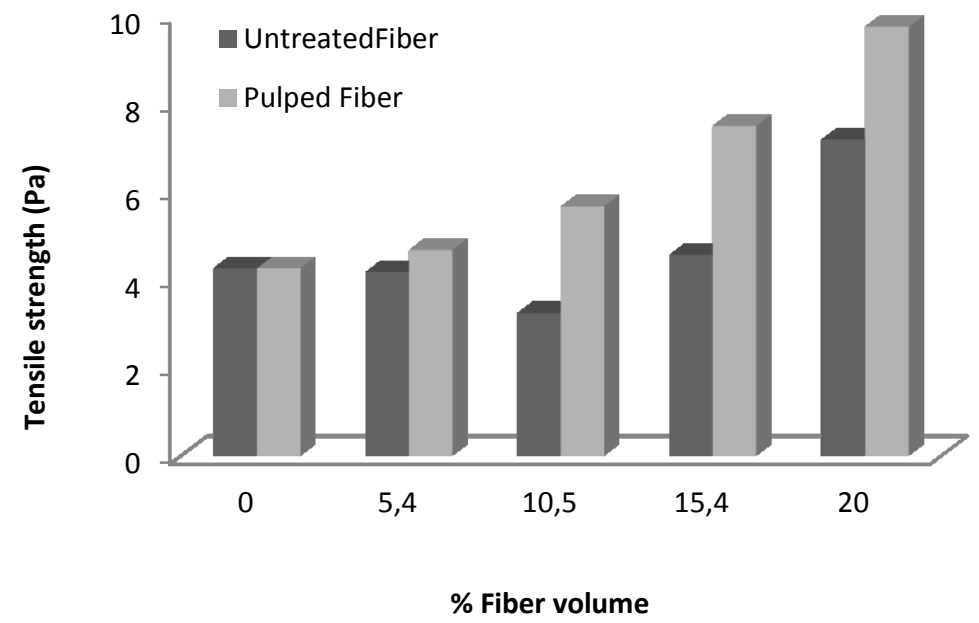

Figure 6: Effect of fiber content on the tensile strength of the composites

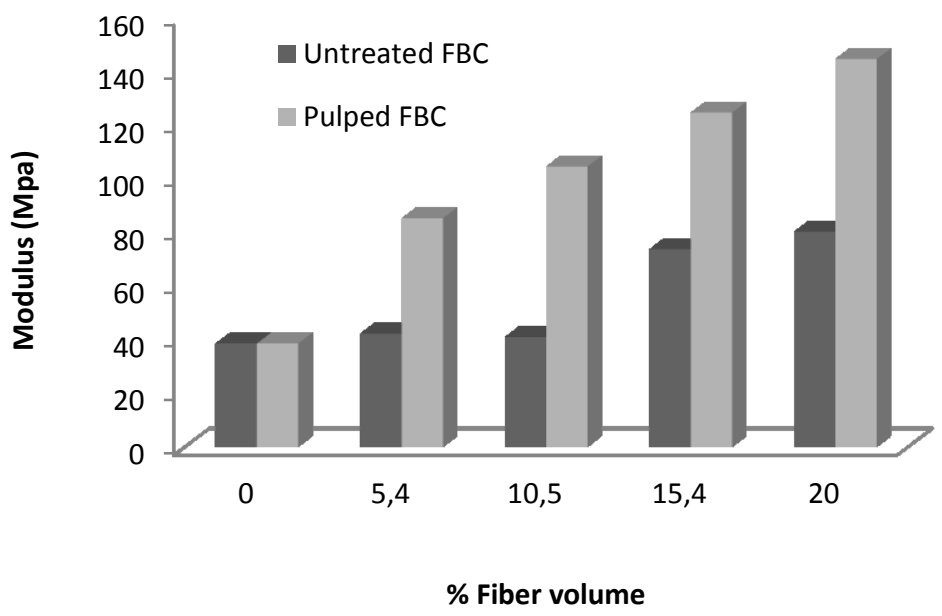

Figure 7: Effect of fiber content on the tensile modulus of the composites 


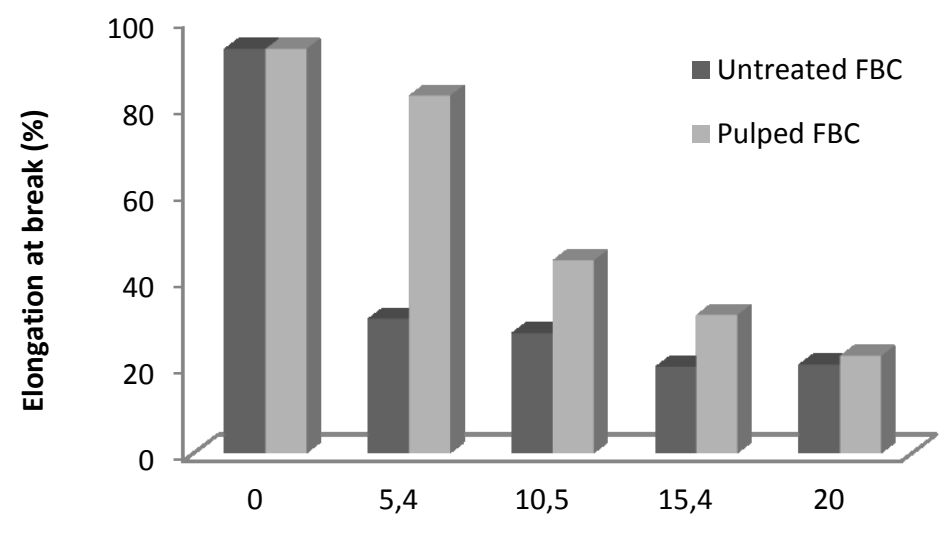

$\%$ Fiber volume

Figure 8: Effect of fiber content on the elongation properties of composites

\subsection{SEM and FTIR spectra}

A scanning electron microscope was employed to examine the surface morphology of the banana fiber reinforced LDPE composite. The SEM image of the fiber polymer matrix is shown in Figure 9. The result showed that the composites showed good bonding of stalk fiber with the low density polyethylene matrix and there was no evidence of fiber pull - out from the polymer matrix.

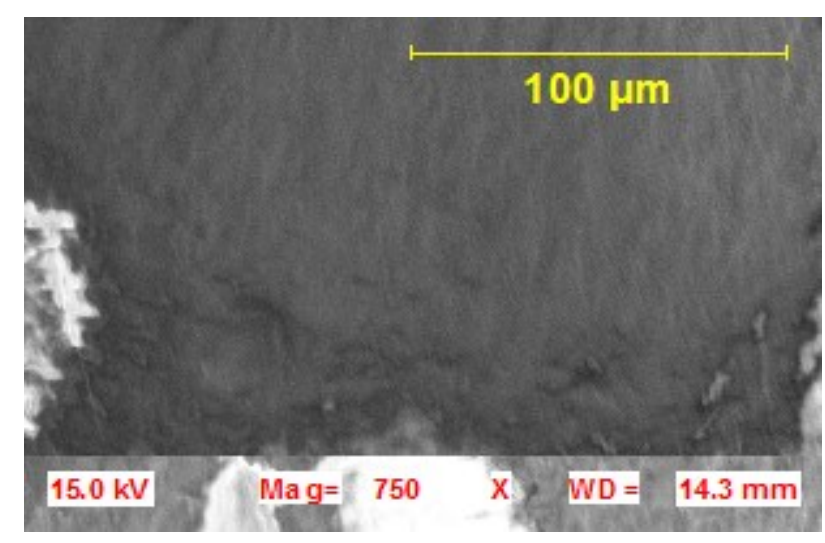

Figure 9: SEM image of the $5 \%$ banana fiber reinforced LDPE composite

The FTIR spectra of the treated and pulped fiber are shown in Figure 10. The major difference was the increase in the intensity of the spectral after the pulping of the fiber. The medium broad band at 3466.64 $\mathrm{cm}^{-1}$ is attributed to the $\mathrm{O}-\mathrm{H}$ stretch vibration of the intermolecular hydrogen bonding associated with cellulose fibers [26]. This band became sharp and intense after soda pulping of the fiber and it appears at $3447.78 \mathrm{~cm}^{-1}$ (Figure $7 \mathrm{~b}$ ). The intensity has been attributed to the removal of impurities from the surface of the fibers by the soda pulping liquor thus exposing the more reactive - $\mathrm{OH}$ group [32]. Similarly, the weak C-H stretch around 2923 and $2843 \mathrm{~cm}^{-1}$ in the untreated fiber became more intensified after pulping due to the exposure of the functional group. The peak at $1631 \mathrm{~cm}-1$ and $1415 \mathrm{~cm}-1$ may be due to the $\mathrm{O}-\mathrm{H}$ bending and $\mathrm{CH}_{2}$ deformation which shifted slightly to a higher frequency after soda treatment. Other peaks in the range $1160-898 \mathrm{~cm}^{-1}$ characteristics of C-O stretch of COH or C-O-C also became prominent after treatment. Thus, the treatment of the fiber releases the reactive group in the fiber for better bonding with the polymer [33].

\section{CONCLUSIONS}

Banana stalk fiber, a natural fiber, has good potential as a viable and alternative reinforcement in the pro- 
duction of low density polyethylene composites. Weak fiber-matrix interaction of fiber-reinforced composites can readily be overcome through fiber modification and pretreatments. Both untreated and soda pulped banana stalk fiber were sucessfully used to reinforce the polyethylene matrix. Composite reinforced with the treated fiber showed improved physical and mechanical properties over that reinforced with untreated fibers. The tensile properties of the composites increased with increasing fiber content.
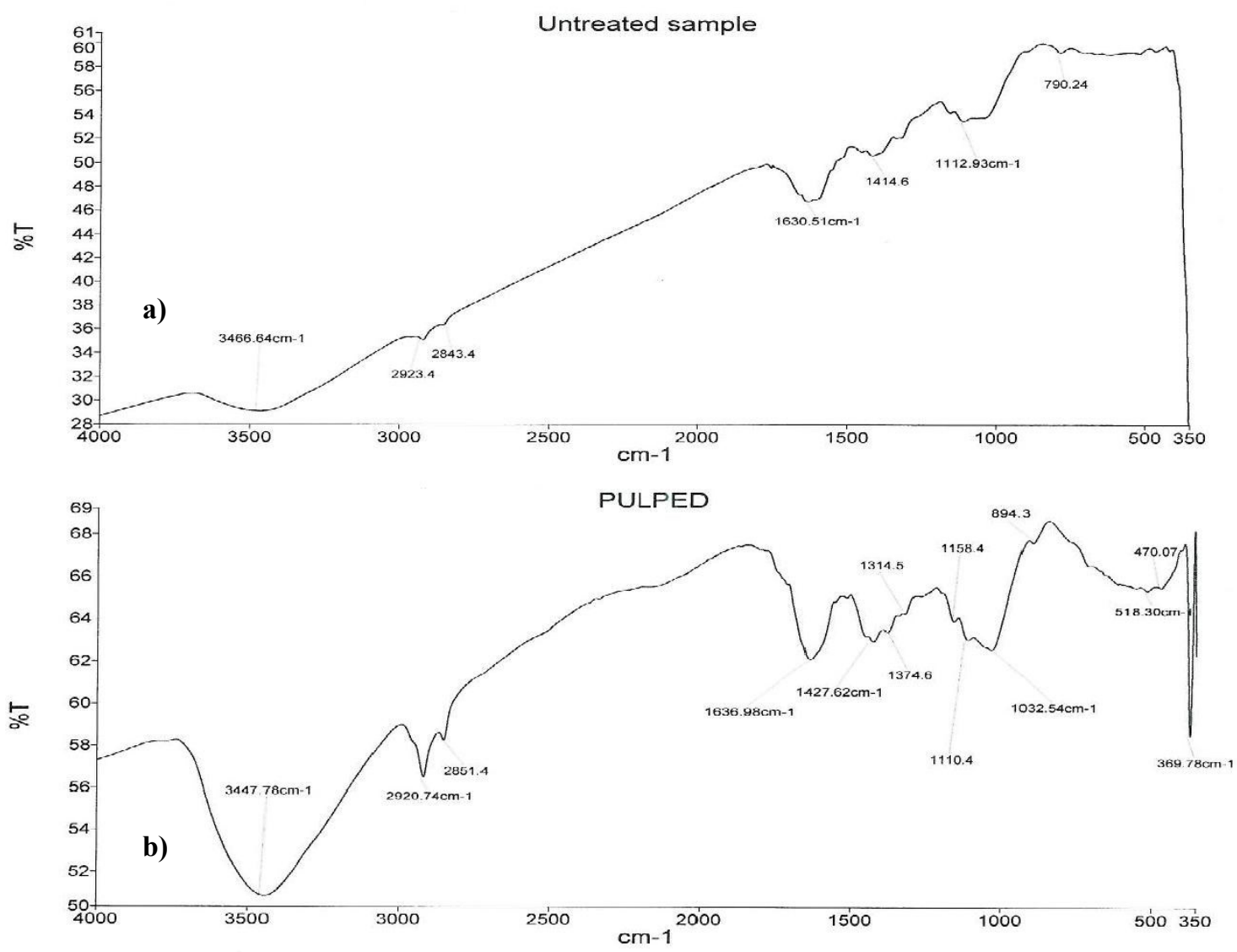

Figure 10: FTIR spectral of the (a) treated and (b) pulped BSF

\section{ACKNOWLEDGMENTS}

The authors wish to acknowledge the Senate Research Grants (SRG/FS/2010/3 ${ }^{A}$ ) from the University of Ibadan, Nigeria.

\section{BIBLIOGRAPHY}

[1] RAGHAVENDRA, S., LINGARAJU, P., SHETTY, S., et al., "Mechanical properties of short banana fiber reinforced natural rubber composites", International Journal of Innovative Research in Science, Engineering and Technology, v. 2 pp. 1652 - 1655, May 2013.

[2] SHANKS, R. A., HODZIC, A., WONG, S., "Thermoplastic biopolyester natural fiber composites", Journal of applied polymer science, v. 91, n.4, pp. 2114 -2121, Feb. 2004.

[3] VAN DE VELDE, K., KIEKENS, P., "Thermal degradation of flax: The determination of kinematic parameters with thermo gravimetric analysis", Journal of Applied Polymer Science, v.83, pp. $2634-2643$, 2002.

[4] ANUAR, H., HASSAN, N.A., FAUZEY, F. M., Compatibilized PP/EPDM-kenaf fibre composite using melt blending method, Advanced Materials Research, v. 264-265, pp. 743 - 747, Jun. 2011. 
[5] ZAMAN, H. U., KHAN, M. A., KHAN, R. A., "Physico-mechanical and degradation properties of banana fiber/ldpe composites: effect of acrylic monomer and starch", Composite Interfaces, v. 18, pp. 685 700, Apr. 2011.

[6] FUNG, K. L., XING, X.S., LI, TJONG, S.C., et al, "An investigation on the processing of sisal fiber reinforced polypropylene composites”, Composites Science and Technology, v. 63, n. 9, pp. 1255-1258, Jul. 2003.

[7] KELLER, A., "Compounding and mechanical properties of biodegradable hemp fiber composites", Composites Science and Technology, v. 63, pp. 1307-1316, 2003.

[8] SAPUAN, S.M., LEENIE, A., HARIMI, M., et al., "Mechanical properties of woven banana fibre reinforced epoxy composites", Materials and Design, v. 27, n.8, pp. 689 - 693, Dec. 2006.

[9] POTHAN, L. A., GEORGE, C. N., JOHN, M. J., et al., "Dynamic mechanical and dielectric behavior of banana-glass hybrid fiber reinforced polyester composites", Journal of Reinforced Plastics and Composites, v. 29, pp. 1131-1145, 2010.

[10] RAMESH, M., SRI ANANDA ATREYA, T., ASWIN, U.S., et al., "Processing and mechanical property evaluation of banana fiber reinforced polymer composites", Procedia Engineering, v. 97, pp. 563 - 572 , Dec. 2014.

[11] GHOSH, R., RAMAKRISHNA, A., REENAC, G., et al., "Water absorption kinetics and mechanical properties of ultrasonic treated banana fiber reinforced-vinyl ester composites", Procedia Materials Science, $\mathrm{v} .5,311-315$, Sep. 2014

[12] BLEDZKI, A. K., MAMUN, A.A., FARUK, O. “Abaca fibre reinforced PP composites and comparison with jute and flax fibre PP composites”, Express Polymer Letters, v.1, 755 - 762, Nov. 2007.

[13] ARIFUZZAMAN KHAN, G. M., ALAM SHAMS, M. S., KABIR, MD. R., et al., "Influence of chemical treatment on the properties of banana stem fiber and banana stem fiber/coir hybrid fiber reinforced maleic anhydride grafted polypropylene/low-density polyethylene composites", Journal of Applied Polymer Science Special Issue: Fibers, v. 128, n.2, pp. 1020-1029, Apr. 2013.

[14] PRASAD, V., AJIL JOY,V., VENKATACHALAM, S., et al ., "Finite element analysis of jute and banana fibre reinforced hybrid polymer matrix composite and optimization of design parameters using anova technique", Procedia Engineering, v. 97, pp. 1116 - 1125, Dec. 2014

[15] BHOOPATHI, R., RAMESH, M., DEEPA, C., "Fabrication and property evaluation of banana-hempglass fiber reinforced composites”, Procedia Engineering, v. 97, pp. 2032 - 2041, Dec. 2014.

[16] VENKATESHWARAN, N., ELAYAPERUMAL, A., "Banana fiber reinforced polymer composites a review”, Journal of Reinforced Plastics and Composites, v. 29, n. 15, pp. 2387 - 2396, Aug. 2010.

[17] SRINIVASAN, V. S., BOOPATHY, S. R., SANGEETHA, D., et al., "Evaluation of mechanical and thermal properties of banana-flax based natural fibre composite", Materials and Design, v. 60, pp. 620 - 627, 2014.

[18] PRACElla, M., HAQUE, M. D. M., AlvareZ, V., "Functionalization, Compatibilization and Properties of Polyolefin Composites with Natural Fibers", Polymers, v. 2, n. 4, pp. 554 - 574, Nov. 2010.

[19] EZEMA, I.C., MENON, A.R.R., EDELUGO, S.O., et al., "Ply tensile properties of banana stem and banana bunch fibres reinforced natural rubber composite", Nigerian Journal of Technology (NIJOTECH), v. 31, n. 1, pp. 25 - 30, Mar. 2012.

[20] OMOTOSO, M. A., OGUNSILE, B. O., "Fibre and chemical properties of some Nigerian grown Musa species for pulp aproduction”, Asian Journal of Material Science, v. 1, pp. 14 - 21, 2009.

[21] Franklin, G.L. "A rapid method for softening wood for anatomical analysis", Trop. Woods, v. 88, pp. 35 36, 1954.

[22] GRANT, J., Digestion experiments. In: A laboratory handbook of pulp and paper manufacture, $2^{\text {nd }}$ Edition, Edward Arnold (Publishers) Ltd, pp. 49-53, 1961.

[23] SGRICCIA, N., HAWLEY, M.C., MISRA, M. "Characterization of natural fiber surfaces and natural fiber composites”, Composites: Part A, v. 39, pp: 1632-1637, 2008.

[24] FERRER, A., VARGAS, F., JAMEEL, H., et al., "Influence of operating variables and model to minimize the use of anthraquinone in the soda-anthraquinone pulpinp of barley straw", BioResources, v. 10, n. 4, pp. 6442-6456, 2015. 
[25] RAI, A., JOSHI, Y.P., “Applications and Properties of Fibre Reinforced Concrete”, Int. Journal of Engineering Research and Applications, v. 4, n. 5, pp. 123-131, 2014.

[26] JIANG, L., HUANG, J.J., QIAN, J., et al., "Study of poly(3-hydroxybutyrate-co-3hydroxyvalerate)(PHBV) bamboo pulp fiber composites: Effects of nucleation agent and compatibilizer", Journal of Polymers and the Environment, v. 16, n. 2, pp. 83-93, 2008.

[27] GIRONES, J., ESPINACH, F.X., PELLICER, N., et al., "High -performance-tensile-strength alphagrass reinforced starch-based fully degradable composites", BioResources, v. 8, n. 4, pp. 6121-6135, 2013.

[28] OGUNSILE, B.O., OMOTOSO, M.A., ONILUDE, M.A. "Comparative physicochemical properties and soda pulps from the mid-rib, pseudostem and stalk of Musa paradisiaca", Journal of Biological Sciences, v.6, n. 6, pp. 1047 - 1052, 2006.

[29] MARIATTI, M., JANNAH, M., BAKA, A. A., et al., "Properties of banana and pandanus woven fabric reinforced unsaturated polyester composites", Journal of Composite Materials, v. 42, pp. 931 - 941, May. 2008.

[30] ASHORI, A., SHESHMANI, S., "Hybrid composites made from recycled materials: Moisture absorption and thickness swelling behavior", Bioresource Technology, v. 101, pp. $4717-1720,2010$.

[31] RASIDI, M.S., HUSSEINSYAH, S., LENG, T.P., "Chemical modification of Nypa fruticans filled polylactic acid/recycled low-density polyethylene biocomposites", BioResources, v. 9, n. 2, pp. 2033-2050, 2014 [32] NDAZI, B.S., KARLSSONB, S., TESHAA, J.V., et al., "Chemical and physical modifications of rice husks for use as composite panels", Composites: Part A v. 38, n. 3, pp. 925 - 935, Mar. 2007.

[33] RANGEL-VÁZQUEZ, N. A., LEAL-GARCÍA, T., "Spectroscopy Analysis of Chemical Modification of Cellulose Fibers", J. Mex. Chem. Soc., v. 54, pp. 192-197, 2010. 